Crop Breeding and Applied Biotechnology 16: 22-27, 2016

Brazilian Society of Plant Breeding. Printed in Brazil

\title{
ARTICLE
}

http://dx.doi.org/10.1590/1984-70332016v16n1a4

\section{Construction and characterization of a bacterial artificial chromosome library of the maize inbred line Qi319}

\author{
Chun Hua Mu ${ }^{1,2}$, Yu Yang ${ }^{3}$, Fa Jun Zhang ${ }^{1}$, Wen Cai Li ${ }^{1}$, Shou Ping Lu ${ }^{1}$, Zhao Dong Meng ${ }^{1}$, Xia Liu ${ }^{1,2^{*}}$ and Guang Cun $\mathrm{Li}^{3}$
}

Received 17 November 2014

Accepted 12 August 2015

\begin{abstract}
Zea mays L. has been the most cultivated crop and the crop with the largest yield in China since 2012. We constructed a bacterial artificial chromosome (BAC) library for the maize inbred line Qi319, which may be used as a key source for disease-resistant maize breeding in China. The BAC contains 270,720 clones, with an average insert size of $90 \mathrm{~kb}$. The coverage of the library is about 10.43 genome equivalents when considering a haploid genome size of $2300 \mathrm{Mb}$, providing a $99.99 \%$ likelihood of isolating any maize gene or sequence in the library. An average of 12 clones were obtained by polymerase chain reaction screening by using primer pairs linked to the genes for resistance to maize southern rust and rough dwarf. The results indicate that the library can satisfy the requirements for recovering specific sequences. The library is available to researchers to whom it may be of interest.
\end{abstract}

Key words: Maize, inbred line, resistance genes, bacterial artificial chromosome library.

\section{INTRODUCTION}

Zea mays L. (maize) belongs to the grass family (Gramineae). Since 2012, it has been the crop with the largest cultivated area and highest yield in China (National Bureau of Statistics of China, 2012). The incidence and prevalence of maize diseases affect yield; maize southern rust caused by Puccinia polysora Underw. and rough dwarf disease caused by the rice black-streaked dwarf virus are limiting factors that cause significant losses and a decline in crop quality (Ma et al. 2010, Zhang et al. 2010, Wang et al. 2010, Cao et al. 2013). With the development of plant genetic engineering, identifying resistance genes and developing resistant varieties by genetic engineering techniques are fundamental for improving plant resistance. However, the genes that confer resistance to these maize diseases have not been cloned. The original studies on these genes mainly focused on inheritance regulation and mapping (Chen et al. 2004, Jines et al. 2007, Ma et al. 2010, Zhang et al. 2010). Given the advantages of high cloning efficiency, good stability, easy preparation, and ease of manipulation, the bacterial artificial chromosome (BAC) cloning system is an invaluable tool for gene cloning and structural and functional analyses (He et al. 2010).
BAC libraries have been developed for numerous major crops, including Arabidopsis (Choi et al. 1995), rice (Zhang et al. 1996), wheat (Lijavetzky et al. 1999), cotton (Hu et al. 2011), potato (Li et al. 2011), and Chinese cabbage (Feng et al. 2011). In 2009, the first physical genome map for maize was established using the B73 BAC library with the cooperation of Iowa State University and Cold Spring Harbor Laboratory. The map promoted studies on gene mapping, cloning, and gene function.

Some important resistance genes or quantitative trait loci (QTLs) have been located and cloned, and their functions have been identified using BAC libraries. $S c m v 1$, the gene that confers resistance to sugarcane mosaic virus (SCMV) disease, was predicted based on the publicly available B73 genome sequence (Tao et al. 2013). The candidate genes qRgls1 and qRgls2 that confer resistance to maize gray leaf spot (GLS) were identified using Y32 and B73 BACs (Xu et al. 2014). The qHSR1 gene for resistance to head smut and the qMrdd1 gene for resistance to rough dwarf disease were sequenced based on the Mo17 and 1145 BAC libraries, respectively.

\footnotetext{
${ }^{1}$ Maize Research Institute, Shandong Academy of Agricultural Sciences, Jinan, Shandong 250100, China *E-mail: snakepy@126.com

${ }^{2}$ Shandong Provincial Key Laboratory of Crop Genetic Improvement, Ecology and Physiology, Jinan Shandong 250100, China

${ }^{3}$ Vegetable Research Institute, Shandong Academy of Agricultural Sciences, Jinan, Shandong 250100, China
} 
The inbred line Qi319 has been used for many years in China as the core material for maize breeding because of its excellent resistance, good general combining ability (GCA), and wide adaptability. Here, we constructed a BAC library for Qi319 and tested its quality. The positive clones for maize southern rust and rough dwarf disease were identified using the linking markers as probes. We believe that the library can provide the essential resources for advanced map-based gene cloning, comparative genomic research, and breeding for disease resistance.

\section{MATERIAL AND METHODS}

\section{Materials}

The inbred line Qi319, a desirable parent for some hybrids in China, was used to construct a BAC and test its quality. This inbred line is highly resistant to the main diseases of the Huanghuaihai maize area, including stalk rot, rough dwarf disease, maize rust, and leaf blight (Ye 2000). A study showed that $97.8 \%$ of germplasms of Qi319 belonged to PB (Xie et al. 2007), which is a heterotic group mainly from the tropical maize zone, with the main advantage of excellent disease resistance. Qi319 is completely different from B73 because $79.6 \%$ of its germplasm is from the BSSS (including Reid) (Xie et al. 2007), a highly important heterotic group in the temperate maize zone.

\section{High-molecular-weight (HMW) DNA isolation}

Qi319 plants were grown in the dark at $28^{\circ} \mathrm{C}$ for $7 \mathrm{~d}$ in a controlled growth chamber. DNA was isolated from young leaves and the top parts of the plants. Ten grams of young leaves were ground in liquid nitrogen. Nuclei were released by incubating the cell extract at $4{ }^{\circ} \mathrm{C}$ for $20 \mathrm{~min}$ in $0.1 \% \beta$-mercaptoethanol plus $1 \times$ nuclear extraction buffer (NEB: TKE $100 \mathrm{~mL}$, sucrose $171.2 \mathrm{~g}$, spermidine $1.0 \mathrm{~g}$, tetrahydrochloride spermine $0.35 \mathrm{~g}, \beta$-mercaptoethanol 0.45 $\mathrm{mL}$, ascorbic acid $1.0 \mathrm{~g}$, PVP-40 $20.0 \mathrm{~g}$, sodium diethyl carbamate disulfide $1.3 \mathrm{~g}$, final volume to $1 \mathrm{~L}$; TKE: $0.1 \mathrm{M}$ Tris, $1.0 \mathrm{M} \mathrm{KCl}$, 0.1 M EDTA, pH 9.4-9.5). To eliminate cell debris, the leaf homogenate was successively filtered through two layers of Miracloth $(250 \mu \mathrm{m})$ (Calbiochem/ EMD Biosciences, Inc., Billerica, MA, USA) and then added to $5 \mathrm{~mL}$ fresh NEB plus $0.1 \% \beta$-mercaptoethanol and $10 \%$ Triton X-100. The mixture was incubated on ice for $15 \mathrm{~min}$. The nuclei pellet was centrifuged at $850 \times \mathrm{g}$ for $10 \mathrm{~min}$ at $4{ }^{\circ} \mathrm{C}$. The nuclei pellet was washed in $20 \mathrm{~mL} 1 \times$ NEB without $\beta$-mercaptoethanol and Triton X-100, and then centrifuged at $850 \times g$ for $10 \mathrm{~min}$ at $4{ }^{\circ} \mathrm{C}$. Finally, the nuclei pellet was resuspended in $300 \mu \mathrm{L} 1 \times$ NEB and embedded in 1.4\% low-melting-point agarose plugs (InCert Agarose,
Cambrex Bio Science, Rockland, Inc., Rockland, ME, USA). Compressed DNA bands were recovered from the agarose gel slices by using an Electro-Eluter model 422 (Bio-Rad). Agarose plugs containing HMW DNA were incubated for $22 \mathrm{~h}$ at $50^{\circ} \mathrm{C}$ in lysis buffer ( $1 \%$ sarkosyl, $50 \mathrm{mg}$ proteinase $\mathrm{K}, 0.4 \mathrm{M}$ EDTA [pH 8.5], and $190 \mathrm{mg} \mathrm{Na}_{2} \mathrm{~S}_{2} \mathrm{O}_{5}$ ) and for 22 $\mathrm{h}$ at $50{ }^{\circ} \mathrm{C}$ in lysis buffer without $\mathrm{Na}_{2} \mathrm{~S}_{2} \mathrm{O}_{5}$, washed for $2 \mathrm{~h}$ at room temperature in TE buffer $(10 \mathrm{mM}$ Tris- $\mathrm{HCl}$ and 10 mM EDTA, pH 8.0) plus $40 \mu \mathrm{g} \mathrm{mL}{ }^{-1}$ (1 mM PMSF) twice, and then washed for $1 \mathrm{~h}$ in TE buffer twice. An extra HMW DNA purification step was conducted with pulsed-field gel electrophoresis (PFGE; $200 \mathrm{~V}, 120^{\circ}, 60$-s switch time and 5-h run time) using a CHEF DRII apparatus (Bio-Rad, Hercules, CA, USA) to eliminate the degraded DNA. Finally, agarose plugs were washed twice for $1 \mathrm{~h}$ in TE at $4{ }^{\circ} \mathrm{C}$ before being used for restriction enzyme digestion.

\section{BAC library construction}

Agarose plugs containing HMW DNA were soaked in 5 $\mathrm{mL}$ HindIII restriction buffer $(1 \times$ NEB buffer plus $100 \mu \mathrm{g}$ $\mathrm{mL}^{-1}$ bovine serum albumin, $8 \mathrm{mM}$ spermidine- $\mathrm{HCl}$, and 1 $\mathrm{mM}$ dithiothreitol) on ice for $1 \mathrm{~h}$, twice. Then, agarose plugs were transferred into new HindIII restriction buffer with 20, 40, and $60 \mathrm{U} \mathrm{mL}^{-1}$ HindIII restriction enzyme, respectively. The reactions were incubated for $1 \mathrm{~h}$ at $37^{\circ} \mathrm{C}$ and then stopped by transferring the plugs to $10 \mathrm{~mL}$ ice-cold $0.5 \mathrm{M}$ EDTA (pH 8.0). Partially digested HMW DNA was subjected to two rounds of size selection by PFGE in $1 \%$ SeaKem GTG agarose gels in $0.5 \times$ Tris-Borate-EDTA at $10^{\circ} \mathrm{C}$. The regions were removed from the latter gel, and DNA was recovered through digestion with GELase (Epicentre, Madison, WI, USA). The size-selected digested DNA was ligated into Hind III-digested and dephosphorylated CopyControl ${ }^{\mathrm{TM}}$ $\mathrm{pCC}^{\mathrm{TM}}$ cloning vector (Epicentre). The ligation reaction was desalted using $0.5 \times \mathrm{TE}$ (diluted with the same volume of double distilled water) for $3 \mathrm{~h}$ before transformation into electrocompetent DH10B cells (Invitrogen, Carlsbad, CA, USA) by using a Q-bot (Genetix Ltd., Christchurch, Dorset, UK). Recombinant colonies were randomly picked by hand from plates containing IPTG $(100 \mu \mathrm{M})$, X-gal $\left(40 \mathrm{mg} \mathrm{L}^{-1}\right)$, and chloramphenicol (12.5 $\left.\mathrm{mg} \mathrm{L}^{-1}\right)$ into 384-well plates containing Luria-Bertani (LB) freezing media. All 384-well plates were incubated overnight at $37^{\circ} \mathrm{C}$, replicated, and then frozen at $-80^{\circ} \mathrm{C}$.

\section{BAC clone characterization}

A total of $150 \mathrm{BAC}$ clones were randomly picked from the library and inoculated at $37^{\circ} \mathrm{C}$ for $24 \mathrm{~h}$. The isolated plasmid DNAs were obtained by mini-preparation using the Sambrook method and completely digested with the 
restriction enzyme NotI (Sigma, St. Louis, MO, USA) for average insert-size analysis. The total volume of the reaction system was $20 \mu \mathrm{L}$ with $2 \mu \mathrm{g}$ DNA and $40 \mathrm{U}$ NotI plasmid DNAs. The digested products were separated using PFGE $\left(6 \mathrm{~V} \cdot \mathrm{cm}^{-1}, 5-15\right.$-s switch time, 14 -h run time, $\left.12.5^{\circ} \mathrm{C}\right)$. The insert size was estimated by comparison with a PFG marker (New England BioLabs, Ipswich, MA, USA).

To test the stability of BAC clones in Escherichia coli, we randomly selected four BACs from the library. The clones were inoculated at $37^{\circ} \mathrm{C}$ for $24 \mathrm{~h}$ with chloramphenicol $(12.5$ $\left.\mathrm{mg} \mathrm{L}{ }^{-1}\right)$. We used $5-\mu \mathrm{L}$ culture to inoculate a subsequent 5 $\mathrm{mL}$ of $2 \times \mathrm{LB}$ media. The procedure was continued for five cycles. Each 24 -h period represented about 20 generations. DNA samples isolated from the first and fifth day cultures were completely digested by EcoRI at $37{ }^{\circ} \mathrm{C}$, and the restriction patterns were detected on agarose gel.

\section{Detection of positive clones by using primers linked to the resistance genes}

\section{Primers for positive clone detection}

According to the results of previous studies (Chen et al. 2004, Zhou et al. 2007, Ma et al. 2010), primers linked to the genes for resistance to maize southern rust and rough dwarf disease were synthesized by Shanghai Shenggong Company (Shanghai, China). Primer phi041 belongs to the SSR marker, and MA7 is a SCAR marker converted from a RAPD fragment. II-1 and II-4 are STS markers converted from RAPD fragments (Table 1).

\section{Filtration of positive BAC clones}

The primers linked to resistance genes were used to identify the positive BAC clones, which were used for physical map construction during cloning of resistance genes. At the same time, we were able to judge the quality of the BAC library based on the results. If the primer is a specific fragment of the maize genome and the library quality is good, we can achieve positive clones at about the same number as the library coverage.
The entire procedure consisted of two steps. First, 384 clones in a 384-well plate were combined into a plate pool. The positive plate was identified with the polymerase chain reaction (PCR)-based markers as primers, and the DNA isolated from the plate pool as a template. Second, every clone of the positive plate was detected by colony PCR. All clones from a positive plate were cultured at $37^{\circ} \mathrm{C}$ for 24 $\mathrm{h}$ with chloramphenicol on LB solid medium. We prepared $25 \mu \mathrm{L}$ PCR master mix for each clone. Sterile toothpicks were used to pick the clones, which were then immersed in master mix. PCR was then under appropriate conditions for each primer, with each protocol beginning with an extension step at $95{ }^{\circ} \mathrm{C}$. The products for primers phi041 and MA7 were detected on $2 \%$ agarose gels, whereas those for II-1 and II- 4 were detected on $1 \%$ agarose gels.

\section{RESULTS AND DISCUSSION}

\section{Construction of the maize BAC library}

Given the rich amount of polysaccharides and fibers produced during leaf maturation, we modified the general library construction procedure. The modifications included using etiolated cotyledon of 7-d-old growing plants as the DNA source, and addition of PVP-40 at a final concentration of $1 \%$ and $\beta$-mercaptoethanol in the extraction-washing buffer to improve DNA quality. The prepared DNA was $\sim 1$ $\mathrm{Mb}$ and was nearly free of protein and organelles, making it suitable for BAC library construction.

DNA separation was performed in two stages. First, HMW DNA embedded in low-melting point agarose plugs was partially digested by the enzyme HindIII at concentrations of 20,40 , and $60 \mathrm{U} \mathrm{mL}^{-1}$ at $37^{\circ} \mathrm{C}$ for $1 \mathrm{~h}$, and the digested DNA was separated by PFGE (Figure 1). The sample exposed to $40 \mathrm{U} \mathrm{mL}^{-1}$ enzyme contained more DNA fragments in the size range of 100-300 kb compared to the two other concentrations.

Second, the recovered gel slice was separated by PFGE a second time, and fragments with sizes ranging from 100-

Table 1. Primers used for positive clone detection

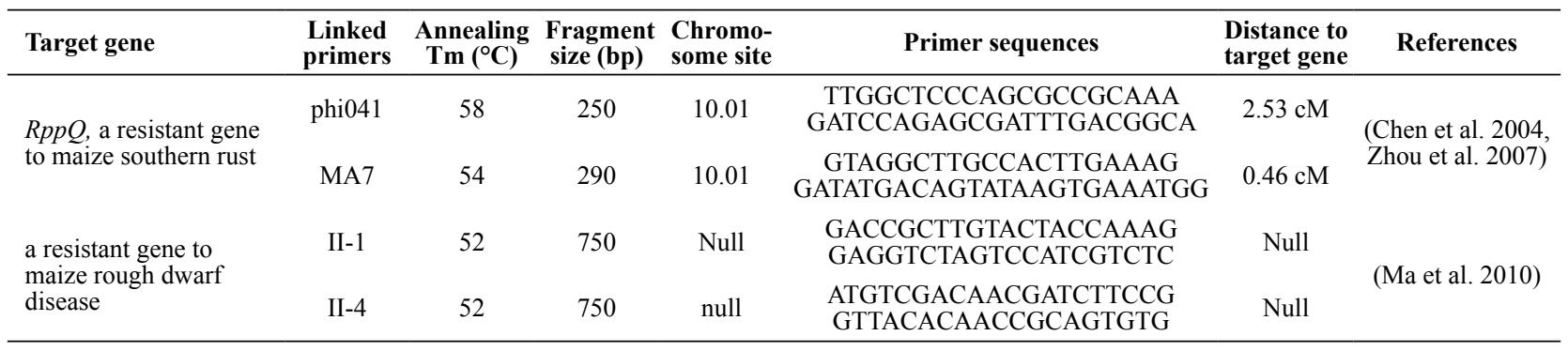




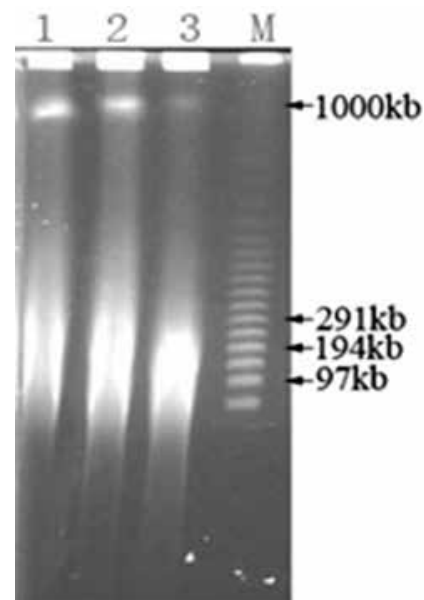

Figure 1. Partial digestion of HMW DNA. Amount of the enzyme Hind III was 20,40 and $60 \mathrm{U} \mathrm{mL}^{-1}$ in lanes 1,2 , and 3, respectively.

$200 \mathrm{~kb}$ and 200-300 kb were excised. Eluted DNA (50 ng) was ligated to vector CopyControl pCC1 (10 ng) by $400 \mathrm{U}$ ligase for $16 \mathrm{~h}$ in a $100-\mu \mathrm{L}$ reaction volume and incubated under temperature-cycle conditions.

There are generally many fragments shorter than the target length after the first PFGE; thus, removing small DNA fragments with a second round of PFGE is necessary (Wang et al. 2001, Feng et al. 2011). This method can improve the quality of the library but decrease transformation efficiency because electrophoresis destroys the sticky ends of the large fragments.

Transformation efficiency of ligation products is a key factor limiting BAC library construction, so we compared the transformation efficiency of 200-300 kb and 100-200 $\mathrm{kb}$ digested DNA fragments. About 4000-5000 white clones with $90 \mathrm{~kb}$ inserted fragments and 400-800 white clones with $140 \mathrm{~kb}$ inserted fragments were achieved by $2 \mu \mathrm{L}$ transformation products of $100-200-\mathrm{kb}$ and $200-300-\mathrm{kb}$ fragments, respectively. That means larger fragments have lower transformation rates with longer inserted fragments. Thus, the $100 \mathrm{~kb}$ to $200 \mathrm{~kb}$ digested DNA fragments were ligated with the vector for the 233 transformations. The entire BAC library consists of 270,720 clones, which are organized into 705 384-well plates.

\section{Quality testing of the BAC library}

\section{Test of insert size and empty clone rate}

A total of 150 clones were selected from the library, and DNA was isolated from the clones to study the insert size distribution and to estimate both the average insert size in the library and the empty clone rate. Isolated DNA was digested by NotI to release the insert, after which it was fractionated by PFGE. We observed several bands, including the vector and restriction fragments from one to five for each BAC-DNA.

Statistical analysis revealed that the insert size of clones ranged from $80-100 \mathrm{~kb}$, with an average size of $90 \mathrm{~kb}$ (Figure 2). Up to $1.33 \%$ of clones had no insert. Based on the maize genome size of 2,300 Mb (Schnable et al. 2009), the library contains approximately 10.43 haploid genome equivalents. The probability of recovering any specific sequence of interest is $>99 \%$ across the library.

\section{Test of clone stability}

EcoRI restriction patterns of four BAC clones in 20 and 100 generations were obtained to test the stability of BAC clones in E. coli. No visible changes were observed in the patterns of fragments between 20 and 100 generations, indicating good BAC stability (Figure 3).

\section{Identification of positive clones}

To verify the genome coverage of the library for special fragments, positive clones were scanned using SSR, STS, and SCAR primers as probes. Eight and 14 positive clones

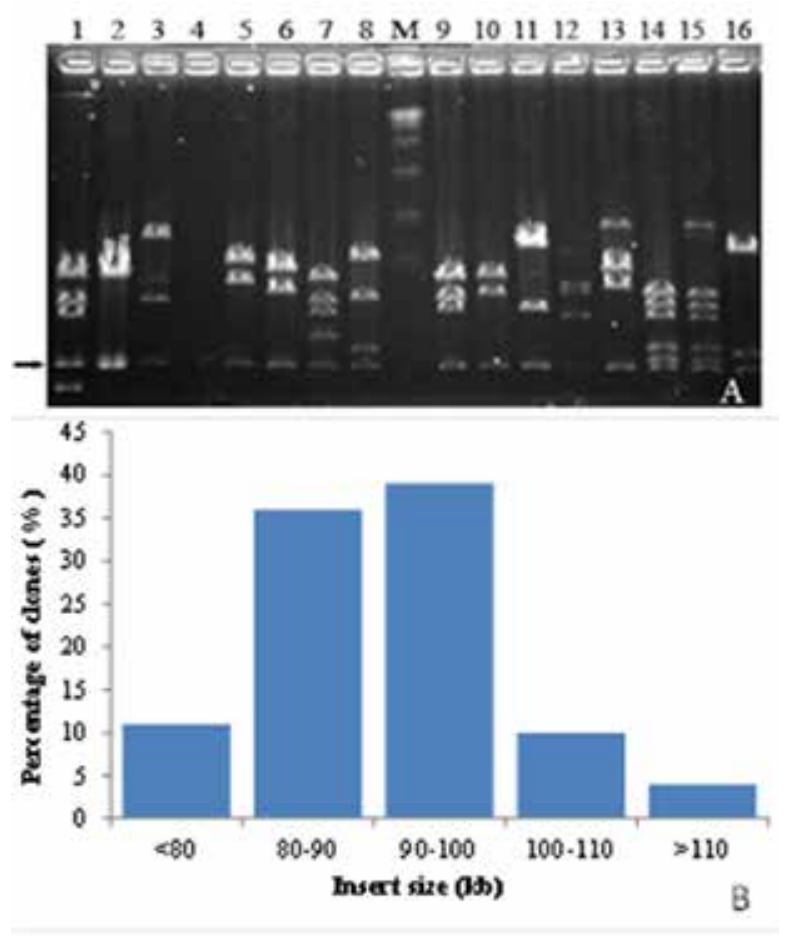

Figure 2. Evaluation of insert size of BAC clones (A) and distribution of BAC clone insert sizes (B). M: Lambda ladder pulsed-field gel (PFG) marker; $1-16$ refers to clones selected from the library. 


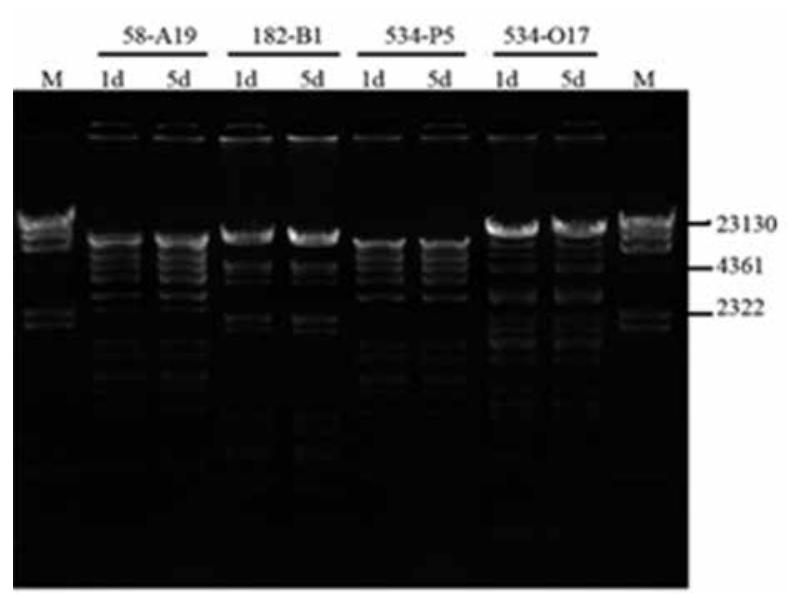

Figure 3. Stability analysis of bacterial artificial chromosome (BAC) clones. M: $\lambda \mathrm{DNA} /$ HindIII; $1 \mathrm{~d}, 5 \mathrm{~d}$ : days for clone inoculation; $58-\mathrm{A} 19$, 182-B1, 534-P5, and 534-O17: the clone in the library.

Table 2. Number of hits detected by some linked markers in the bacterial artificial chromosome (BAC) library

\begin{tabular}{lcc}
\hline Disease & $\begin{array}{c}\text { Resistance gene- } \\
\text { linked markers }\end{array}$ & $\begin{array}{c}\text { Number of posi- } \\
\text { tive clones }\end{array}$ \\
\hline Maize southern rust & phi041 & 8 \\
& MA7 & 14 \\
Maize rough dwarf & II-1 & 15 \\
Average & II-4 & 11 \\
\hline
\end{tabular}

were identified using primers phi041 and MA7, respectively, which were linked to genes for resistance to maize southern rust located on the short arm of chromosome 10. Fifteen and 11 positive clones were picked using primers II-1 and II-4, respectively, which were linked to genes for resistance to rough dwarf disease (Table 2). Thus, the average number of positive clones that could be achieved from the library using a probe was 12 .

Efficient library screening is crucial for all applications of the library. PCR screening is a popular method because of its reliability, speed, and efficiency, with high specificity. We used a two-step PCR screening procedure based on the BAC library pool system and compared it with three-step (Hu et al. 2011) and four-step (Cong-Fen and Komatsuda 2004) PCR screening procedures. The PCR numbers for positive clones detected by different methods are shown in Table 3. The two-step method can save time in identifying positive clones, given the high PCR throughout and reduced costs of PCR today.

Although it is unclear whether the target gene is covered by the selected BAC clones, this positive clone identification is an important step in arriving at the resistance genes through this method. In the next step, positive clones can be lined up to form an initial contig, which is the basis of chromosome walking. The overlap of two BACs was verified by (1) restriction mapping and (2) analysis of sequencing of PCR products through BAC end markers (Li et al. 2011).

\section{ACKNOWLEDGMENTS}

This research was supported by the Natural Science Foundation of Shandong Province (No. ZR2012CQ033), Shandong, China; the National Key Project for Breeding Genetically Modified Organisms (No. 2008ZX08003-001), Beijing, China; Shandong Academy of Agricultural Sciences Research Fund for Youth (No.2014QNM23), Shandong, China; and the National Natural Science Foundation of China (No. 31301271), Beijing, China.

Table 3. Polymerase chain reaction (PCR) number for positive clones detected using different screening methods

\begin{tabular}{lccc}
\hline & $\begin{array}{c}\text { Two-step assay } \\
\text { (Present study) }\end{array}$ & $\begin{array}{c}\text { Three-step assay } \\
\text { (Hu et al. 2011) }\end{array}$ & $\begin{array}{c}\text { Four-step assay } \\
\text { (Cong-Fen and Komatsuda 2004) }\end{array}$ \\
\hline Step I & 100 & 100 & 10 \\
Step II & 384 & 24 & 10 \\
Step III & & 16 & 96 \\
Step IV & & & 4 \\
\hline Total & 484 & 140 & 120 \\
\hline
\end{tabular}

\section{REFERENCES}

Cao XL, Lu YG, Di DP, Zhang ZY, Liu H, Tian LZ, Zhang AH, Zhang YJ, Shi LD, Guo BH, Xu J, Duan XF, Wang XB, Han CG, Miao HQ, Yu JL and Li DW (2013) Enhanced virus resistance in transgenic maize expressing a dsRNA-specific endoribonuclease gene from E. coli. PLoS One 8: e60829.

Chen CX, Wang ZL, Yang DE, Ye CJ, Zhao YB, Jin DM, Weng ML and
Wang B (2004) Molecular tagging and genetic mapping of the disease resistance gene $R p p Q$ to southern corn rust. Theoretical and Applied Genetics 108: 945-950.

Choi S, Creelman RA, Mullet JE and Wing RA (1995) Construction and characterization of bacterial artificial chromosome library of Arabidopsis thaliana. Plant Molecular Biology Reporter 13: 124-128. 
Cong-Fen HE and Komatsuda T (2004) PCR-base screening BAC library and direct end sequencing of BAC clones. Acta Genetica Sinica 31: 1262-1267.

Feng DL, Shi XP, Yang Y, Wang YH, Xuan SX, Zhao JJ and Shen SX (2011) Construction and characterization of a bacterial artificial chromosome library from Chinese cabbage. Acta Horticulturae Sinica 38: 151-158.

He JP, Ruan SL, Zhu SJ and Ma HS (2010) The application and evaluation of map-based gene isolation in crops. Hereditas 32: 903-913.

Hu Y, Lu YM, Ma D, Guo WZ and Zhang TZ (2010) Construction and characterization of a bacterial artificial chromosome library for the A-Genome of cotton (G. arboreum L.). Journal of Biomedicine and Biotechnology 2011: 1-5.

Jines MP, Balint-Kurti P, Robertson-Hoyt LA, Molnar T, Holland JB and Goodman MM (2007) Mapping resistance to southern rust in a tropical by temperate maize recombinant inbred topcross population. Theoretical and Applied Genetics 114: 659-667.

Li G, Huang S, Guo X, Li Y, Yang Y, Guo Z, Kuang H, Rietman H, Bergervoet M, Vleeshouwers VG, Vossen EAvd, Qu D, Visser RG, Jacobsen E and Vossen JH (2011) Cloning and characterization of $\mathrm{r} 3 \mathrm{~b}$; members of the $\mathrm{r} 3$ superfamily of late blight resistance genes show sequence and functional divergence. Molecular Plant-Microbe Interactions 24: 1132-1142.

Lijavetzky D, Muzzi G, Wicker T, Keller B, Wing R and Dubcovsky J (1999) Construction and characterization of a bacterial artificial chromosome (BAC) library for the A genome of wheat. Genome 42: 1176-1182.

Ma X, Cui DZ, Liu HH, Liu X, Ning LH and Chen HB (2010) Development of sts-pcr markers for maize rough dwarf virus resistant genes. Journal of Maize Science 18: 61-64.

National Bureau of Statistics of China (2012) Avaliable at $<$ http://data. stats.gov.cn/workspace/index;jsessionid=6F8B1F26A174F757DB65
8F458424A3F4?m=hgnd $>$ Accessed on Jan 31, 2014

Schnable PS, Ware D, Fulton RS, Stein JC, Wei F, Pasternak S, Liang C, Zhang J, Fulton L and Graves TA (2009) The B73 maize genome: complexity, diversity, and dynamics. Science 326: 1112-1115.

Tao YF, Jiang L, Liu QQ, Zhang Y, Zhang R, Ingvardsen CR and Frei UK (2013) Combined linkage and association mapping reveals candidates forScmv1, a major locus involved in resistance to sugarcane mosaic virus (SCMV) in maize. BMC Plant Biology 13: 162-164.

Wang WM, Jiang GH, Wang SQ, Zhu LH and Zhai WX (2001) Construction of a deep coverage rice bac library and identification of clones associated with disease-resistant genes. Acta Genetica Sinica 28: $120-128$.

Wang XM, Shi J, Jin QM, Li X and Sun SX (2010) Handbook of maize diseases and insect pests. China Agricultural Science and Technology Press, Beijing, p. 20-32.

Xie CX, Zhang SH, Li MS, Li XH, Hao ZF, Bai L, Zhang DG and Liang YH (2007) Inferring genome ancestry and estimating molecular relatedness among 187 Chinese maize inbred lines. Journal of Genetics and Genomics 34: 738-748.

Ye JC (2000) The first inbred lines Qi319 immune to maize southern rust bred in China. Scientia Agricultura Sinica 33: 110.

Zhang H, Choi S, Woo S, Li Z and Wing R (1996) Construction and characterization of two rice bacterial artificial chromosome libraries from the parents of a permanent recombinant inbred mapping population. Molecular Breeding 2: 11-24.

Zhang Y, Xu L, Zhang DF, Dai JR and Wang SC (2010) Mapping of southern corn rust-resistant genes in the W2D inbred line of maize (Zea Mays L.). Molecular Breeding 25: 433-439.

Zhou C, Chen C, Cao P, Wu S and Sun J (2007) Characterization and fine mapping of $R p p Q$, a resistance gene to southern corn rust in maize. Molecular Genetics and Genomics 278: 723-728. 